\title{
Macronutrient intake and prevalence of markers of metabolic syndrome in white UK adult males in the National Diet and Nutrition Survey Rolling Programme 2008-2014
}

\author{
T. Harrison ${ }^{1}$, K.E. Lane ${ }^{1}$, L.M. Boddy ${ }^{2}$, F. Amirabdollahian ${ }^{3}$ and I.G. Davies ${ }^{1}$ \\ ${ }^{1}$ School of Sport Studies, Leisure and Nutrition, Liverpool John Moores University, Liverpool, L17 6BD, \\ ${ }^{2}$ School of Sports and Exercise Sciences, Liverpool John Moores University, Liverpool, L3 3 AF and \\ ${ }^{3}$ School of Health Sciences, Liverpool Hope University, Liverpool, L16 9JD
}

The amount of carbohydrates recommended for consumption by current dietary guidelines has been challenged in relation to their suitability to prevent or manage cardiometabolic (CM) diseases with suggestions that they should be decreased and replaced by protein or fat ${ }^{(1,2)}$. Others have argued that a more personalised approach is required ${ }^{(3)}$. Aim of this investigation was to assess the potential impact of lower versus higher consumption of dietary macronutrients and prevalence of CM risk markers in a representative sample of the UK male white population.

Unweighted data from 642 white adult males aged 19 and over in the National Diet and Nutrition Survey Rolling Programme ${ }^{(4)}$ (NDNS RP) 2008-2014 with or without metabolic syndrome (MetS) ${ }^{(5)}$ were analysed for associations of dietary macronutrient intake as percentage food energy $(\% \mathrm{FE})$ with $\mathrm{CM}$ risk markers. Logistic regression analysis (adjusted for age group and smoking status) was used to compare the odds ratios [OR] of prevalence of individual markers of MetS between the lowest and highest quartiles of dietary macronutrient intake as $\% \mathrm{FE}$ ( $\leqslant 44$ vs. $\geq 52$ for carbohydrates; $\leqslant 31$ vs. $\geq 39$ for fats; $\leqslant 15$. vs. $\geq 19$ for protein).

There was a significant $(\mathrm{p}<0.05)$ reduction in likelihood of MetS $(\mathrm{OR}, .55 ; 95 \%$ confidence interval [CI], .34 to .84), and elevated waist circumference (OR, .50; $95 \% \mathrm{CI}, .30$ to .83$)$ and glucose levels (OR, $.51 ; 95 \% \mathrm{CI}, .30$ to .87$)$ for those in the highest quartile of carbohydrate $\% \mathrm{FE}$ intake compared to the lowest quartile, whereas those in the highest quartile of protein $\% \mathrm{FE}$ intake had a significantly $(\mathrm{p}<0.05)$ increased risk of presenting with the same markers of MetS (OR, 1.75; $95 \%$ CI, 1.05 to 2.93; OR, 2.12; $95 \%$ CI, 1.24 to 3.63 ; and OR, $2 \cdot 15 ; 95 \%$ CI, 1.25 to 3.70 respectively). Those with the highest compared to the lowest total dietary fat intake also presented with elevated $\mathrm{CM}$ risk markers, albeit these findings were not significant.

\begin{tabular}{|c|c|c|c|c|c|c|c|c|c|}
\hline & \multicolumn{3}{|c|}{$\mathrm{CHO} \% \mathrm{FE}$} & \multicolumn{3}{|c|}{$\mathrm{FAT} \% \mathrm{FE}$} & \multicolumn{3}{|c|}{$\mathrm{PROT} \% \mathrm{FE}$} \\
\hline & \multirow[b]{2}{*}{ OR } & \multicolumn{2}{|c|}{$95 \% \mathrm{CI}$ for OR } & \multirow[b]{2}{*}{ OR } & \multicolumn{2}{|c|}{$95 \%$ CI for OR } & \multirow[b]{2}{*}{ OR } & \multicolumn{2}{|c|}{$95 \%$ CI for OR } \\
\hline & & Lower & Upper & & Lower & Upper & & Lower & Upper \\
\hline MetS* & $.55^{\mathrm{a}}$ & .34 & .84 & 1.58 & .97 & $2 \cdot 56$ & $1.75^{\mathrm{a}}$ & $1 \cdot 05$ & $2 \cdot 93$ \\
\hline TRIG & .72 & .46 & $1 \cdot 14$ & $1 \cdot 36$ & .86 & $2 \cdot 15$ & $1 \cdot 18$ & .73 & 1.91 \\
\hline HDL-C & $1 \cdot 13$ & .69 & 1.87 & $1 \cdot 19$ & .71 & 1.98 & .86 & .50 & 1.47 \\
\hline WC & $.50^{\mathrm{a}}$ & .30 & .83 & $1 \cdot 28$ & .78 & $2 \cdot 10$ & $2 \cdot 12^{\mathrm{a}}$ & $1 \cdot 24$ & 3.63 \\
\hline GLUC & $.51^{\mathrm{a}}$ & .30 & .87 & 1.46 & .86 & $2 \cdot 47$ & $2 \cdot 15^{\mathrm{a}}$ & $1 \cdot 25$ & $3 \cdot 70$ \\
\hline $\mathrm{BP}$ & .89 & .53 & 1.49 & $1 \cdot 38$ & .81 & $2 \cdot 34$ & $1 \cdot 19$ & .68 & $2 \cdot 06$ \\
\hline
\end{tabular}

*Metabolic Syndrome (MetS) definition: 3 out of 5 of the following: triglycerides (TRIG) $\geq 1.7 \mathrm{mmol} / \mathrm{L}$; High-density lipoprotein cholesterol (HDL-C) $\leqslant 1.03 \mathrm{mmol} / \mathrm{L}$ for males; Waist circumference (WC) $\geq 94 \mathrm{~cm}$ for white males; Glucose (GLUC) $\geq 5.6 \mathrm{mmol} / \mathrm{L}$; Blood pressure (BP) $\geq 130 \mathrm{mmHg}$ systolic or $\geq 85 \mathrm{mmHg}$ diastolic respectively; $\mathrm{CHO} \% \mathrm{FE}$ - total carbohydrates percentage food energy; FAT $\% \mathrm{FE}$ - total fats food energy; PROT $\% \mathrm{FE}-$ total protein food energy; OR - odds ratio (adjusted for age group and smoking status), $1^{\text {st }}$ vs. $4^{\text {th }}$ quartile of intake; CI - confidence interval; a p $<0.05$

Further investigations need to confirm whether the quality of the macronutrients consumed and overall diet quality ${ }^{(6)}$ has had an impact on these results. In the context of a personalised approach to nutrition future cohort studies should also provide data that allow for examining inter-individual variations in responses to dietary macronutrients, especially carbohydrates, to achieve optimum CM health for a larger proportion of the population.

1. Henderson G, Zinn C \& Schofield G (2017) Lancet 389, 589.

2. Hu T \& Bazzano LA (2014) Nutr Metab Cardiovasc Dis 24, 337-43.

3. Noecker C \& Borenstein E (2016) Trends Mol Med 22, 83-85.

4. Link to UK Data Archive. http://www.esds.ac.uk/findingData/snDescription.asp?sn=6533.

5. Alberti KG, Eckel RH, Grundy SM et al. (2009) Circulation 120, 1640-5.

6. Schwingshackl L \& Hoffmann G (2015) J Acad Nutr Diet 115, 780-800. 